\title{
A Firm-Specific Study of the Impact of Media Coverage on Capital Flow
}

\author{
Yang Jiang, Weizhong Ma, Xiangbin Yan
}

\author{
Harbin Institute of Technology \\ Harbin 150001, P.R. China \\ E-mail.jiangyanghit@126.com,mawz@hit.edu.cn,xbyan@hit.edu.cn
}

cross $^{\text {ref }}$ http://dx.doi.org/10.5755/j01.ee.27.1.12237

\begin{abstract}
This study aims to investigate whether and how firm-specific media coverage can impact the capital flow decisions of investors in China's stock market. The media dataset includes articles about 42 listed financial companies that were published in three major securities newspapers from 2004 through 2013. A multidimensional perspective analysis is chosen to capture both the amount and content sentiment of media coverage. Specifically, the quantity model is built to investigate the impact of article amount on capital flow, while the quality model aims to capture the difference in media impact between positive news and negative news. In order to control the unobserved heterogeneity of firms, fixed effects model is employed. Our empirical analysis demonstrates that media coverage can significantly influence the capital flow decisions of investors; this holds for both the quantity aspect and the quality aspect. The quantity model shows that after controlling for risk factors such as size and book-to-market ratio, more capital flow will be allocated to the high-return stocks with high media coverage. The quality model finds that stocks with positive media coverage will be allocated more capital flow than those with negative media coverage, given an identical stock return. Furthermore, a simple but effective identification strategy is constructed to explore the mechanism behind this media coverage and capital flow relationship. Our results suggest that the information view does not offer sufficient explanation power; instead media coverage tends to be more about "attention-grabbing" than conveying information.
\end{abstract}

Keywords: Media Coverage, Stock Return, Capital Flow, Firm-Specific, Multidimensional, Fixed Effects Model.

\section{Introduction}

Social media has been widely discussed in various research fields, such as E-commerce, finance and others. The stock market, which is highly information sensitive, also witnesses the impact from social media (Fang \& Peress, 2009). Media coverage is a feasible vehicle for enhancing information transparency via a third party instead of merely relying on company information releases. As Sakalauskas et al. (2015) pointed out, the transparency of financial data can affect investors' expectations and finally reflect in stock price.

The reality of stock market activity necessitates this strand of study. The media and investors represent the supply and demand sides, respectively. On the demand side, information asymmetry exists between listed companies and investors, even among investors. Yet the information reflected by the stock price is insufficient to support investors in their decision making. Faced with a wide variety of information such as historical price information, publicly available information and internal information, the majority of nonprofessional investors are unable to identify and distinguish real information from non-factual information in media reports. On the supply side, the media has an edge in information disclosure, transmission, interpretation and other related aspects. As Solomon (2012) pointed out, investors often use media to help them process and determine the importance of information. Media can assist investors in disseminating and processing information, reducing information asymmetry and market uncertainty.

Existing research has largely focused on the possibility of using media coverage to predict the future performance of stocks, such as predicting the stock price (Dyck \& Zingales, 2003), return (Fang \& Peress, 2009) and volatility (Aman, 2011). Other researchers also examine different types of media coverage such as political news and economic news (Chan et al., 2001). All these studies proved the necessity and plausibility of media-stock relationship studies. Some studies focus on cash flow, such as Solomon et al. (2014), who analyzed investors' capital allocation decisions in the context of mutual fund transactions. Since the investment process, in its very nature, is a capital allocation decision process, topics on the relationship between media coverage and capital flow are very important. However, previous work hasn't fully captured the impact of media coverage on investors' capital flow decisions, in particular, at the firm-specific level. Therefore, in this paper, we seek to provide evidence in this direction by investigating the impact of media coverage on capital flow, using firm-specific examples from the stock market in China.

The purpose of this paper is to explore the relationship between media coverage and the investors' capital flow at the firm-specific level. Solomon et al. (2014) defined the fund flow as the percentage change in total net asset that is not driven by fund returns. In this paper, we follow their direction and use the net assets per share to measure capital flow. We study three questions. First, does media coverage of stocks affect an investor's capital allocation decision? If so, does it exacerbate or attenuate? Second, does the quantity of media coverage affect capital flow? And lastly, to what extent is capital flow influenced by the sentiment of media coverage? 
In this paper, stocks in the financial sector, which are highly information sensitive, are selected as our stock sample. The media sample contains articles collected from three widely circulated national security newspapers in China: China Securities Journal, Shanghai Securities News and Securities Times. We selected these media as our sample for several reasons. First, these newspapers are regulated by China Securities Regulatory Commission for stock disclosure. Second, media coverage in these newspapers is more relevant and contains less noise news. Moreover, the timeless electronic version and the large portal website transshipment make this media coverage available to investors through online channels. In terms of the empirical analysis, a baseline fixed effects panel model is first introduced to explore the net impact of previous year's return on the capital flow in the following year, and then we introduce a multidimensional analysis which incorporates both quantity and quality aspects. The former captures the amount of media coverage, while the latter considers and measures the difference between positive and negative media coverage (Stephen, 2008). These two dimensions could give a relatively complete picture of the media coverage. Another problem we are concerned with is the mechanism behind these potential impacts. To tackle the mechanism, we build an identification strategy. This paper does not aim to give a complete and absolute explanation of the information view and attention view. What we do is to give a concise but efficient explanation of their relative power.

Our main finding is that media coverage of stocks in the preceding period has significant impact on investors' capital flow decisions in the subsequent period. Two specific results are as follows. First, for stocks ranked in the top $30 \%$ in terms of media coverage amount, one unit change in the previous year's return will bring a 1.1136 unit change in the following year's capital flow, indicating an inflow of capital by the investors. Meanwhile, for those stocks ranked in the bottom $30 \%$ in terms of media coverage amount, a one unit change in the previous year's return will bring a relatively small total effect of 0.0644 units, which is not significant. Second, under positive media coverage, a one unit increase in the previous year's return can bring a total inflow of 0.5979 units in the following year, compared to the stocks which receive negative coverage.

These results indicate that investors will allocate more capital flow to past winners with more media coverage than to identical stocks with less media coverage. And if a past loser receives high media coverage, there will be more pronounced reduction in its following year's capital flow than identical stocks with low media coverage. On the quality side, past winners with positive media coverage tend to attract more capital flow in the following year than stocks with the same high return but negative media coverage. For past losers, the reduction in the following year's capital flow is more pronounced with negative news. Similarly, the reduction in the following year's capital flow is more pronounced in past loser stocks with positive coverage, compared to stocks with similar low return but negative media coverage.

The paper broadens the existing literature in two aspects. Firstly, it supplements studies of the relationship between the media and stock market by using firm-level evidence from the stock market and media coverage in China. We offer insight into whether and how media coverage impacts capital flow in the sensitive financial industry, using data from January 1, 2004 through December 31, 2013. By taking the quantity and quality dimension of media coverage into account, this study examines the extent to which these two dimensions can exacerbate or attenuate the basic impact. Secondly, an identification strategy is constructed to gain understanding of the mechanism underlying the media coverage and capital flow relationship. To explore the relative power of information view and attention view, the proxy of turnover is used. Our results suggest that the information view does not offer sufficient explanation power; instead media coverage tends to be more about "attention-grabbing" than conveying information.

By introducing media coverage into this study, our results support that investors are less sophisticated than expected; they have a tendency to invest in media-favored stocks. Thus, it is possible that investors are not able to capture the true value of stocks that attract their limited attention. This raises the necessity for deeper study such as introducing media coverage rather than traditional micro or macro factors.

\section{Literature Review}

There is a large amount of literature on the relationship between media coverage and multiple financial markets. Papers related to this study are discussed below.

The literature on the impact of media coverage on stock price, return and volatility is the foundation of media and financial markets research, and also offers basic guidance for our study. Pilinkus and Boguslauskas (2009), and Zalgiryte et al. (2014) considered the relationship between macroeconomic factors and stock price. Dyck and Zingales (2003) found stock price reacts strongly to media-reported earnings. Veldkamp (2006) suggested that when the volatility of the asset market increases, news coverage intensifies. More news coverage is correlated with higher asset prices and higher cross-market price dispersion. Fang and Peress (2009) found that a larger amount of media coverage is associated with lower stock return. They first put forward the concept of "media effect," which illustrates the phenomenon that stocks with low media coverage tend to get a higher return than those with high media coverage. Cutler et al. (1989) documented that media coverage does not affect stock return if no major macroeconomic events are occurring. Chen et al. (2011) suggested that financial news in the Wall Street Journal plays an important role in conveying value-related information. The media coverage decreases investors' reaction to unexpected earnings. As to the online media literature, Bank et al. (2011) showed that search volume boosts future returns, and more Google search queries are associated with higher trading activity and greater liquidity. Aman (2011) found that the amount of media coverage is positively correlated with volatility. More media coverage means more information, thus smaller volatility. Other studies include (Da et al., 2011; Dopuch et al., 1986). Those studies prove the necessity of 
media-stock relationship research. In this paper, we follow these previous studies and adopt newspaper coverage to specify media coverage, because it is more professional and trustworthy to long-term investors. Electronic versions make it compatible with online news.

Another strand of literature that relates to our study is about media coverage characteristics and their impact on the price, return and volatility. Some researchers consider the type of news. Chan et al. (2001) examined the influence of political news and economic news on intraday trading activity. Using the Hang Seng Index, they find that political news is more influential than economic news.

Other studies find evidence of the importance of positive news and negative news. Fernandez et al. (2011) used data from the information and communications technology industry to examine investors' reaction to non-financial corporate news. Suleman (2012) established a univariate asymmetric GARCH model to study the stock market's reaction to different types of political news. They report that political news that conveys good news could increase the return of KSE100 index and reduce its volatility, whilst negative political news will increase the volatility and reduce the returns; the influence of negative news is almost twice that of positive news. Chan (2003) studied the relationship between news headlines and stock return, and found that headline stocks show return persistence, especially those with negative information. However, no headline stocks manifest return reversal, especially small stocks. Tetlock (2007) selected Wall Street Journal columns to quantitatively study the interaction between the media and the stock market and found that the media's negative perceptions of stocks will have a downward pressure on the stock price, and then prices will reverse to the average. From the perspective of linguistics, Tetlock et al. (2008) studied the impact of media content on stock returns. Carretta et al. (2011) examined Italy's major financial newspaper Il Sole 24 Ore and found that when news is publicly available, the news content (positive or negative) and the news tone (strong or weak) will affect investors. The work specifies the possibility of distinguishing between news content or news sentiment, which is either positive or negative. This inspired us to add media sentiment to the quality analysis when studying the media coverage and capital flow relationship. We adopt market-based sentiment measures for its relevance to the stock market.

Research on the impact of media on the securities composition is also relevant. Fang et al. (2011) analyzed the relationship between mutual fund transactions and mass media coverage; their results show that mutual funds prefer to buy stocks that have received large media reporting. Solomon et al. (2014) showed that media coverage can affect fund constitution. The fund's cash flow is more sensitive to the return of stocks that are highly reported by the media, whereas the return of no media coverage stocks does not affect capital flow. These studies are directly related to our study. Yet they mainly focus on the stocks in a fund, while we explore the stocks in an industry. This paper examines the existence of media coverage impact and also investigates the extent to which the media-capital flow relationship varies.

When discussing the role of the media in the stock market, two views are prevalent in the existing literature. They may give us insight into the mechanism of the relationship between media coverage and the stock market. The information view or "investor awareness hypothesis" is motivated by the model of neglected securities (Merton, 1987). It holds that in a market of incomplete information, investors need to get news from the media. Tetlock (2011) suggested that media coverage can accelerate the information transmission between investors and the company, thus reducing information asymmetry. Fang et al. (2011) demonstrated that the media also reduces the search costs of investors. Another hypothesis, attention view, is motivated by the behavioral literature. It holds that the media is "attention-grabbing," they attract investors' attention and affect their trading activities in the securities market. Kahneman (1973) pointed out that attention is a scarce cognitive resource and has a propensity to be selective. Individuals are often susceptible to the influence of media coverage when facing large amounts of securities. They lack both financial expertise and time to process mass information. Barber and Odean (2008) believed that media draws the investors' attention to certain types of securities and increases their short-term demand for these stocks. Fang and Peress (2009) pointed out that media coverage could reduce the cost of investment and improve market efficiency. Fang et al. (2011) suggested that institutional investors also suffer from limited attention when choosing stocks, even though these behaviors may be detrimental to fund performance. Yahui et al. (2012) measured media-induced attention and analyzed how media coverage affects the configuration of investor attention. In addition, researchers also differentiate the net impact of media coverage from other factors (Kerl, Schurg, \& Andreas, 2014; Solomon, 2012; Engelberg \& Parsons, 2011). This strand of study inspires us in how to explore the underlying mechanism behind the media coverage and capital flow relationship. In this paper we develop an identification strategy to investigate the mechanism, using turnover as the proxy for testing.

To summarize, previous research on the media-stock relationship varies, yet little work has been done in analyzing the impact of media coverage on the investor's capital flow decision, in particular, at a firm-specific level. Our paper will seek to study this by investigating the impact of media coverage on capital flow, using a firm-specific sample from the financial industry in China.

\section{Data and Descriptive Statistics}

\section{Stock selection}

Stock market investors prefer to deal with firm-level information, rather than industry information (Peng \& Xiong, 2006). Since the financial industry is proficient in information disseminating and processing, it is a suitable sample for an information-related study. In this paper, we select stock data from financial firms. Data is collected from the RESSET/TB, a comprehensive financial research database in China.

Based on the Industry Classification Guidelines for Listed Companies (2012 Revision), we selected financial sector stocks listed in the Shanghai and Shenzhen Stock 
Exchange. According to this standard, the financial industry contains four subdivision industries: Monetary and Financial Services, Capital Market Services, Insurance and other financial Industry. To obtain a valid sample, we exclude stocks listed less than two years and those with missing data. According to previous stock market studies, the $\mathrm{B}$ shares and $\mathrm{H}$ shares are ruled out. B shares aim at the investors outside mainland China and are subscribed by the according currencies. $\mathrm{H}$ shares are issued to Hong Kong investors and subscribed by the Hong Kong dollar. As a result, these two types of shares are unique in aspects of information disclosure requirements, the policy environment and freedom of market, as well as the composition and maturity of investors. Finally, we get a sample of 42 financial companies that matches our media coverage date range of January 1, 2004 through December 31,2013 . We use yearly data because the capital allocation is a long-term investment process, and the stock market undergoes both ups and downs during the sample period, thus it is biased against the various market conditions.

\section{Media sample}

Our media sample contains three widely circulated national security newspapers in China: China Securities Journal, Shanghai Securities News and Securities Times. These three newspapers are the designated information disclosure media by China Securities Regulatory Commission (CSRC). Media coverage in these newspapers is professional, objective and highly related to the stock market. Investors can subscribe to these newspapers either on their official website or offline. Further, their media coverage is also shared by major Chinese portals such as Sina, Sohu and Nete. Therefore, the media sample guarantees the breadth and timeliness of media coverage.

3. Media articles

For each stock, we use newspaper articles as the proxy for its media coverage. We match the stock sample and the media coverage as follows. We use the full company name and its shortened form as keywords to search for firm-specific articles. To get a valid media coverage sample, we first rank the search results by the degree of relevance during the time period. Then we exclude articles that are unrelated to the company's actual activities or do not contain depth reports and exclude stocks that are mentioned less than three times between January 1, 2004 through December 31, 2013. The media article dataset is obtained from CCND, a full-text database of China's major newspapers. Articles in the database come from more than 700 kinds of publicly published major newspapers since 2000. The database is updated by the CNKI Center website and database exchange service center daily.

We construct a measure to capture media coverage. Considering the possible different scope of these newspapers, we choose the circulation of each newspaper in 2013 as weight. The media coverage adjusted by the circulation is defined as follows.

$$
\text { MedCover }_{i t}=\sum_{j=1}^{3} W_{\text {med }_{j}} \text { NumMed }_{i j t}
$$

MedCover ${ }_{i t}$ represents the number of media articles about stock i during period t. $W_{\text {med }_{j}}$ denotes the circulation of newspaper $\mathrm{j}$ in 2013. NumMed ${ }_{i j t}$ represents the amount of media coverage about stock $\mathrm{i}$ during period $\mathrm{t}$ by newspaper j. j = 1 denotes China Securities Journal, j = 2 denotes Securities Times, $\mathrm{j}=3$ denotes Shanghai Securities News, respectively.

4. Summary Statistics

After matching the media coverage with stock data, we get our total sample. Table 1 reports summary statistics for our main variables. As can be seen, the average number of media articles per stock during the sample interval is 21.2996, with a standard deviation of 26.4796 . The stock gets a mean return of $0.2615 \%$ and a standard deviation of 1.0773. The mean of net assets per share equals 4.8644 , indicating that one share holds the capital value of 4.8644 , with the standard deviation being 3.4363 .

Table 1

Summary Statistics for Variables (2004-2013)

\begin{tabular}{|l|l|c|c|c|c|}
\hline \multicolumn{1}{|c|}{ Variables } & \multicolumn{1}{c|}{ Description } & Mean & Std. & Min. & Max. \\
\hline MedCover & Number of articles per stock per year & 21,2996 & 26,4796 & 0,0000 & 281,0000 \\
\hline Ret & Yearly logarithmic return & 0,2615 & 1,0773 & $-0,7691$ & 10,8524 \\
\hline Naps & Net asset per share (yuan/share) & 4,8644 & 3,4363 & $-3,3400$ & 22,7400 \\
\hline Volat & Yearly volatility based on return & 0,4926 & 0,7652 & 0,1133 & 9,5351 \\
\hline Volum & Trading volume (in shares) & $9,28 \mathrm{e}+09$ & $1,08 \mathrm{e}+10$ & $1,66 \mathrm{e}+08$ & $7,97 \mathrm{e}+10$ \\
\hline BM & Book-to-market ratio (\%) & 0,4778 & 0,2847 & 0,0103 & 1,4712 \\
\hline Mktvalue & Market value (yuan) & $9,28 \mathrm{e}+09$ & $1,08 \mathrm{e}+10$ & $1,66 \mathrm{e}+08$ & $1,13 \mathrm{e}+12$ \\
\hline Size & log of tradable market value (yuan) & 24,7315 & 1,4627 & 20,9665 & 28,0700 \\
\hline Turnover & Turnover ratio (\%) & 5,4195 & 1,2308 & 0,7034 & 7,8770 \\
\hline
\end{tabular}




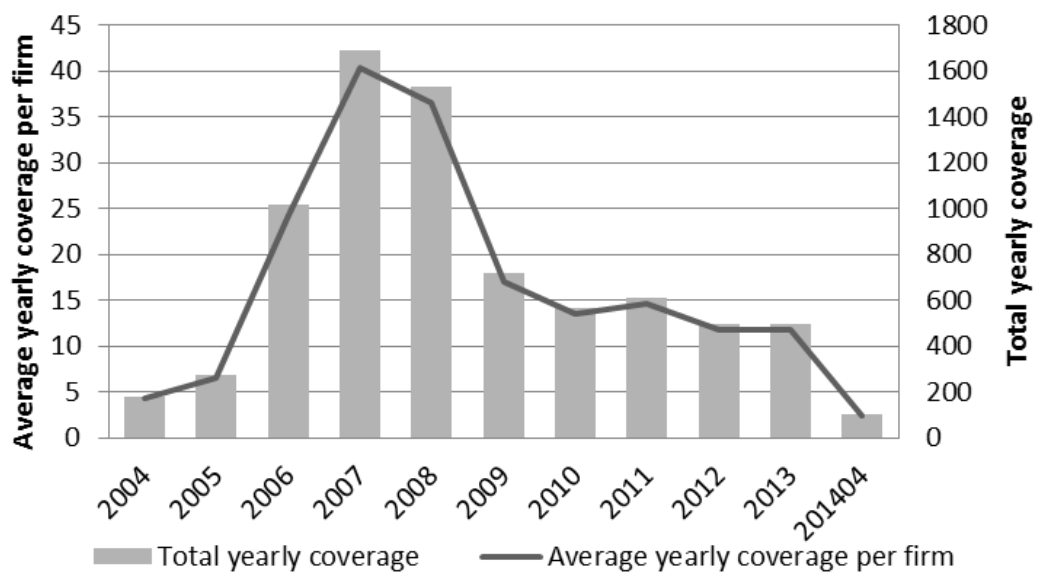

Figure 1. Distribution of Media Coverage

Note: to give a relatively complete description of the media coverage for samples, Figure 1 reports the media coverage up to April 30, 2014. The main analysis is still from January 1, 2004 through December 31, 2013.

Figure 1 reports detailed information about media coverage. It illustrates the annual amount of media coverage across the three newspapers. Shanghai Securities News ranked first, followed by the China Securities Journal and then the Securities Times. Further, the trend of media coverage per stock resembles an inverted U-shaped curve, peaking between the years of 2005 and 2008. Year 2005 witnessed the split-share structure reform. Large-cap stocks such as Bank of China, Industrial and Commercial Bank of China and other super stocks were first issued in 2005, which enhanced the financing and resource allocation function of the capital market. The RMB exchange rate formation mechanism reform in 2007 also restored investor confidence and boosted the development of the capital market. All the above factors lead to a large amount of media coverage.

\section{Empirical Model}

Two empirical issues are of concern. One issue is the existence of media coverage-capital flow effect from both quantity and quality dimensions (in other words, the impact of media coverage on the investors' capital flow decision). Another issue is identifying the mechanism behind the media-capital flow effect, in other words the information or attention view. To answer these questions, we establish an empirical model as follows.

$$
\begin{aligned}
& \text { Flow }_{i t}=\alpha+\beta_{1} \text { ret }_{i, t-1}+\beta_{2} X_{i, t-1} \text { ret }_{i, t-1}+\beta_{3} \text { Volat }_{i, t-1} \\
& +\beta_{4} \text { logVolum }_{i, t-1}+\beta_{5} \text { Size }_{i t}+\beta_{6} \text { BM }_{i t}+\varepsilon_{i t}
\end{aligned}
$$

In Equation (2), the dependent variable is Flow ${ }_{i t}$, defined as the net assets per share in year t. It is used to capture the capital flow as defined earlier, because the net assets per share is a direct measure of the value of the assets that are held by investors.

The independent variables include stock return, volatility and trading volume at year t-1. $X_{i, t-1}$ represents a series of media-related independent variables; the interaction term $X_{i, t-1}$ ret $_{i, t-1}$ is used to capture the impact of media variables on the investors' allocation of capital flow. This interaction term is the variable of interest in our empirical study. Detailed information on $X_{i, t-1}$ will be introduced to the model gradually in the following empirical tests. As other controls, $B M_{i t}$ and Size ${ }_{i t}$ are introduced to control for the potential book-to-market effect and size effect, respectively. Size $e_{i t}$ is computed by the $\log$ transformation of tradable market value for stock $\mathrm{i}$ at year $\mathrm{t}-1$; it represents the stock size.

\section{Media Coverage and Capital Flow}

In order to study the impact of media coverage on capital flow, the baseline model, which documents the main effect, is established first. Then we go a step further to take into account the quantity and quality dimensions of media coverage in our analysis. Our results demonstrate the importance of introducing different media dimensions into the media coverage-capital flow relationship study.

1. Baseline Analysis

Since it is commonly agreed that investors often allocate their capital flow according to the past performance of stocks, we establish a baseline model to capture the net effect from the stock return at year $t-1$ on the net asset value per share at year t. Media-related factors will not be considered in Equation (2).

Column (1) of Table 2 reports a significant positive correlation between stock return and capital flow. A one unit increase in standard deviation of return at previous year t- 1 will bring a $0.3738 \%$ increase in capital flow in the following year $t$. Volatility has negative impact on future capital flow, which indicates that the greater the fluctuation of return in the previous year, the more risk the investors have to bear in the following year, thus the smaller the capital flow. Trading volume also has a negative relationship with the following year's capital flow.

For stock size, each additional one unit increase in the stock size at year t- 1 will bring a 0.5261 unit increase in capital flow in the following year t. The book-to-market ratio is positively correlated to capital flow, with a coefficient of 4.5213 and is significant at the $5 \%$ level. 
This indicates that for those "value stocks" holders, the capital flow will increase in the following year. These results also demonstrate the importance of controlling for firm-specific fixed effects that might stem from the stock size and book-to-market ratio factors.

In summary, the baseline model shows that investors tend to allocate their following year's capital flow according to the previous year's stock return, which we call "capital flow effect" in this paper. Specifically, the higher the previous year's return, the higher the net asset per share in the following year. That is, investors tend to allocate more capital to past winners (stocks with high return in the previous year), and vice versa. This is a benchmark for the below empirical research.

2. Media coverage and investor's capital flow

Media coverage could be described both qualitatively and quantitatively. The quantitative dimension focuses on the amount of media coverage, while the qualitative dimension emphasizes the content sentiment it conveys. Neither can be ignored (Stephen, 2008). Therefore, in this paper we will analyze the impact of media coverage on the investor's capital flow from these two dimensions, which we call "media coverage-capital flow effect" for short.

1) Quantity model: the quantity model aims to analyze the influence of the number of media coverage articles on investors' capital flow decisions. We construct relative media indicators to capture the distribution of the amount of media coverage.

The stocks are first split into three media portfolios according to the absolute number of media articles, including low media coverage (bottom $30 \%$ ), middle media coverage (middle $40 \%$ ) and high media coverage (top $30 \%$ ). Then, two dummy media coverage variables are constructed.

$$
\text { Med }_{1}=\left(\begin{array}{cc}
1 & \text { HighMed } \\
0 & \text { others }
\end{array}\right), \quad \text { Med }_{2}=\left(\begin{array}{cc}
1 & \text { LowMed } \\
0 & \text { others }
\end{array}\right) .
$$

In particular, the interaction term Med $_{1}$ ret $_{i, t-1}$ captures media coverage-capital flow effect for stocks with high media coverage, and $\mathrm{Med}_{2}$ ret $_{i, t-1}$ captures the effect for those low media coverage stocks. The results of the quantity model are reported in column (4) of Table 2.

Column (4) of Table 2 shows that the coefficient of Med $_{1}$ ret $_{i, t-1}$ is 1.0401 and it is statistically significant at the $1 \%$ level. In contrast, the coefficient of $\mathrm{Med}_{2}$ ret $_{i, t-1}$ is not significant with a value of -0.0091 . Coefficients of interaction terms demonstrate that for stocks in the top $30 \%$ of media coverage, a one unit change in the previous year's return will bring a $1.1136(0.0735+1.0401)$ unit change in the following year's capital flow, indicating an inflow of capital by the investors.

Meanwhile, for those stocks in the bottom $30 \%$ of media coverage, a one unit change in the previous year's return will bring a relatively small total effect of 0.0644 (0.0735- 0.0091) units, but this effect is not significant. Meanwhile, consistent with the baseline analysis, stock size is positively related to net asset per share, which indicates that larger size stocks will attract investors to allocate more capital. "Value stocks" (high book-to-market ratio) will bring an increase in the investors' net assets per share.
Table 2

Quantity Results for Media Coverage and Capital Flow

\begin{tabular}{|l|c|c|c|c|}
\hline $\begin{array}{c}\text { Independent } \\
\text { Variable }\end{array}$ & \multicolumn{4}{|c|}{ Dependent Variable } \\
\hline & $\begin{array}{c}(1) \\
\text { Baseline }\end{array}$ & $\begin{array}{c}(2) \\
\text { High media }\end{array}$ & $\begin{array}{c}\text { Low media } \\
\text { Quantity }\end{array}$ \\
\hline ret $_{i, t-1}$ & $0.3470 * *$ & 0.0703 & $0.4731^{*}$ & 0.0735 \\
\hline & 2.0200 & 0.3700 & 2.4800 & 0.3100 \\
\hline Med $_{1}$ ret $_{i, t-1}$ & - & $1.0449 * * *$ & - & $1.0401 * * *$ \\
\hline & - & 3.1900 & - & 2.8100 \\
\hline Med $_{2}$ ret $_{i, t-1}$ & - & - & -0.4709 & -0.0091 \\
\hline & - & - & -1.4900 & -0.0300 \\
\hline Volat $_{i, t-1}$ & $-0.4432 *$ & -0.2728 & -0.1794 & -0.2675 \\
\hline & -1.7100 & -1.0500 & -0.5700 & -0.8600 \\
\hline Volum $_{i, t-1}$ & $-0.4166^{* *}$ & $-0.3692 *$ & $-0.3851 *$ & $-0.3644 *$ \\
\hline & -1.9700 & -1.7700 & -1.8200 & -1.7400 \\
\hline Size $_{i t}$ & $0.5261 * * *$ & $0.4874 * * *$ & $0.5077 * * *$ & $0.4861 * * *$ \\
\hline & 3.1400 & 2.9500 & 3.0300 & 2.9300 \\
\hline BM $_{i t}$ & $4.5213 * * *$ & $4.5741 * * *$ & $4.6515 * * *$ & $4.5823 * * *$ \\
\hline & 7.4500 & 7.6800 & 7.6300 & 7.6100 \\
\hline Intercept & -0.8700 & -1.0804 & -1.3063 & -1.1631 \\
\hline & -0.1700 & -0.2100 & -0.2500 & -0.2200 \\
\hline
\end{tabular}

Note: *** indicates the significance at the $1 \%$ level; $* *$ indicates

significance at the $5 \%$ level; $*$ indicates significance at the $10 \%$ level.

To summarize, after controlling for firm-specific fixed effects factors such as the stock size and book-to-market ratio, our quantity model demonstrates that investors tend to allocate more capital flow to stocks with a high previous year return, and this effect is mainly driven by stocks with higher media coverage. In other words, high return stocks with large media coverage attract more capital flow than identical stocks with similar high return but less media coverage. Similarly, if a low previous year return stock gets high media coverage, there will be more pronounced reduction in its following year's flow than identical stocks with similar low return and low media coverage.

2) Quality model: the quality dimension, which captures media content sentiment such as positive news or negative news, is also introduced into our empirical analysis.

According to literature, there are two main types of proxy for media content sentiment: market-based and content-based (Doran et al., 2012; Das \& Chen, 2007; Pang et al., 2002). The former is based on stock return. The latter is usually constructed from the linguistics perspective by using text mining techniques. To determine the media content sentiment, Tetlock (2007) computed the percentage of words that reflect "positive news" and "negative news" in a text. We argue that the market-based measurement is more in line with the needs of this paper. One reason is that the market-based measure could reflect the objective behavior of market participants directly, while the content measure heavily depends on specific classification algorithms or subjective judgments. If the 
current return is positive, it means that the media conveys positive news, otherwise the media coverage conveys negative news. Another reason is that the market-based measurement reflects the value of media coverage by evaluating stocks' current performance with the expectations of the market, which is a relative indicator. But the content-based measure identifies the media content sentiment by analyzing individual articles in isolation.

This paper defines a dummy variable to capture the media content sentiment. If the media conveys positive news, the Sentimed value is 1 , and if the media coverage passes negative news, the dummy variable value is 0 , thus ${ }_{\text {Sentimed }}=\left(\begin{array}{cc}1 & \text { posinews, } \text { ret }>0 \\ 0 & \text { others, } \text { ret } \leq 0\end{array}\right)$. The interaction term

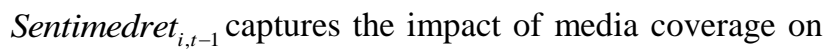
the capital flow from the quality dimension. Results are illustrated in column (3) of Table 3.

Table 3

Quality Results for Media Coverage Sentiment and Capital Flow

\begin{tabular}{|l|c|c|c|}
\hline \multicolumn{1}{|c|}{ Independent } & \multicolumn{3}{|c|}{ Dependent Variable } \\
\hline & $\begin{array}{c}(1) \\
\text { Baseline }\end{array}$ & $\begin{array}{c}(2) \\
\text { Sentiment }\end{array}$ & $\begin{array}{c}\text { Sentiment } \\
\text { with control }\end{array}$ \\
\hline ret $_{i, t-1}$ & $0.3470^{* *}$ & 0.2599 & -0.9454 \\
\hline Sentimedret $_{i, t-1}$ & - & 0.1661 & $1.5433^{*}$ \\
\hline Volat $_{i, t-1}$ & $-0.4432^{*}$ & $-0.6253^{* *}$ & $-0.6471^{* *}$ \\
\hline Volum $_{i, t-1}$ & $-0.4166^{* *}$ & -0.0790 & $-0.4034^{*}$ \\
\hline Size $_{i t}$ & $0.5261 * * *$ & - & $0.4926 * * *$ \\
\hline BM $_{i t}$ & $4.5213^{* * * *}$ & - & $4.8049 * * *$ \\
\hline Intercept & -0.8700 & 6.8163 & -0.6480 \\
\hline
\end{tabular}

Note: *** indicates significance at the $1 \%$ level; $* *$ indicates significance at the $5 \%$ level; * indicates significance at the $10 \%$ level.

Column (3) of Table 3 show that with all variables included, the coefficient of the interaction term is 1.5434 , and it is significant at the $10 \%$ level. This indicates that under positive media sentiment, a one unit increase in the previous year's return can bring a total inflow of 0.5979 $(-0.9454+1.5433)$ units in the following year. The coefficients on size and book-to-market ratio variables are both positive at the $1 \%$ significance level.

To summarize, our quality model shows that after controlling for firm-specific characteristics such as stock size and book-to-market ratio, investors tend to allocate more capital flow to stocks with a high previous year return and this effect is remarkable under positive media sentiment. In other words, stocks with high return and positive media coverage tend to attract more capital flow in the following year, when compared to identical stocks with similar high return but negative media coverage. Similarly, the reduction in the following year's capital flow is more pronounced in stocks with low return and positive coverage, compared to stocks with similar low return but negative media coverage.

\section{The Mechanism behind the Media Coverage -Capital Flow Relationship}

So far, this paper has proved the impact of media coverage on the investors' capital flow, which we call media coverage-capital flow effect in this paper. Next we examine the mechanism behind this effect. To give a concise and efficient explanation of the mechanism, an identification strategy is constructed.

The idea of identify is as follows. Firstly, proxies for plausible views in theory are proposed, and then we examine the relationship between these proxies and the media coverage-capital flow effects. If the view can explain the media-capital flow effect, then the proxy should correlate with the effect; otherwise there won't be a significant relation. In this sense, if the capital flow allocation reaction to media coverage is strongly driven by the information view, then the media coverage-capital flow effect should be significantly correlated with the proxy of information view. On the other side, if the investors' flow allocation reaction to media coverage is driven by attention or other unknown drivers, the above effect may not significantly correlate with this proxy.

As shown in the literature review, two plausible views may explain the underlying mechanism. One possibility is limited attention and the other is the information view. Hou et al. (2009) and Kerl et al. (2014) selected trading volume as a proxy for investors' attention; Solomon et al. (2014) used turnover to measure the efficiency of information. Trading volume and turnover are consistent in spirit. So in this paper we follow these studies and choose turnover as the proxy for the information view. For one thing, turnover could reflect the frequency of the capital flow, which is closely related to our study of investors' capital flow decisions. It also reflects the effectiveness of information. For another, a high turnover indicates a lower effectiveness of media information, which may stem from the lack of valid information in media coverage or be due to the fact that investors fail to fully understand and use the information contained in the media coverage. Under both conditions investors tend to convert their stocks frequently.

Turnover is added to Med $_{1}$ ret $_{i, t-1}$ and Med $_{2}$ ret $_{i, t-1}$ to examine whether information view can affect the media coverage-capital flow relationship. The model is reported in Equation (3).

$$
\begin{gathered}
\text { Flow }_{i t}=\alpha+\beta_{1} \text { ret }_{i, t-1}+\beta_{2} \text { Med }_{1} \text { ret }_{i, t-1}+ \\
\beta_{3} \text { Med }_{2} \text { ret }_{i, t-1}+\beta_{4} \text { TurnMed }_{1} \text { ret }_{i, t-1}+ \\
\beta_{5} \text { TurnMed }_{2} \text { ret }_{i, t-1}+\beta_{6} \text { Volat }_{i, t-1} \\
+\beta_{7} \text { Volum }_{i, t-1}+\beta_{8} \text { Size }_{i t}+\beta_{9} \text { BM }_{i t}+\varepsilon_{i t}
\end{gathered}
$$

According to Equation (3), if the coefficient of TurnMed $_{1}$ ret $_{i, t-1}$ or TurnMed ${ }_{2}$ ret $_{i, t-1}$ is significant, then the difference between a high turnover and low stock turnover has a significant impact on the investors' capital flow decisions. Thus, the information view cannot be rejected. Otherwise, a non-significant coefficient indicates that there is not sufficient support for the information view. The results are presented in column (2) of Table 4 
As can be seen from column (2) of Table 4, as to TurnMed $_{1}$ ret $_{i, t-1}$ and TurnMed ${ }_{2}$ ret $_{i, t-1}$, coefficients are not significant. This suggests that turnover does not have a significant impact on the media coverage-capital flow effect. In other words, the information point of view fails to explain the relationship between media coverage and capital flow. This may be due to the fact that investors don't respond to information that is contained in media coverage, or the media coverage simply plays an attention-grabbing role rather than offering valuable information to investors.

Table 4

Turnovers and Media-Capital Flow Effect

\begin{tabular}{|c|c|c|c|c|}
\hline \multirow{3}{*}{ Independent } & \multicolumn{4}{|c|}{ Dependent Variable } \\
\hline & \multicolumn{2}{|c|}{$\begin{array}{c}(1) \\
\text { Baseline }\end{array}$} & \multicolumn{2}{|c|}{$\begin{array}{c}(2) \\
\text { Turnover interactions } \\
\end{array}$} \\
\hline & Coefficient & Z Stat & Coefficient & Z Stat \\
\hline $\operatorname{ret}_{i, t-1}$ & 0.0735 & 0.3100 & 0.0778 & 0.3300 \\
\hline $\operatorname{Med}_{1}$ ret $_{i, t-1}$ & $1.0401 * * *$ & 2.8100 & -0.5099 & -0.1700 \\
\hline $\mathrm{Med}_{2} \mathrm{ret}_{i, t-1}$ & -0.0091 & -0.0300 & -0.0653 & -0.0200 \\
\hline TurnMed $_{1}$ ret $_{i, t-1}$ & - & - & 0.2453 & 0.5300 \\
\hline TurnMed $_{2}$ ret $_{i, t-1}$ & - & - & 0.0151 & 0.0300 \\
\hline Volat $_{i, t-1}$ & -0.2675 & -0.8600 & -0.3157 & -0.7400 \\
\hline Volum $_{i, t-1}$ & $-0.3644 *$ & -1.7400 & $-0.3836^{*}$ & -1.8200 \\
\hline Size $_{i t}$ & $0.4861 * * *$ & 2.9300 & $0.4916^{* * * *}$ & 2.9500 \\
\hline$B M_{i t}$ & $4.5823 * * *$ & 7.6100 & $4.5494 * * *$ & 7.3700 \\
\hline Intercept & -1.1631 & -0.2200 & -0.8388 & -0.1600 \\
\hline
\end{tabular}

Meanwhile, as Fang et al. (2011) pointed out, "professional investors are subject to limited attention, and such behavior harms their investment performance." So even if media coverage doesn't contain real information, it can divert the attention of investors and increase their demand for these stocks, thus resulting in more capital flow into the higher media coverage stocks. The attention view may therefore provide a relatively reasonable explanation for the above media-capital flow effect.

\section{Conclusions}

The stock market never stops chasing information, which is dominated by the media. Based on a dataset which contains 42 listed financial stocks and three widely circulated security newspapers in China, this paper investigates the existence of the impact of media coverage on capital flow and offers an analysis of the underlying mechanism. Our main findings are as follows.

Firstly, media coverage has significant impact on capital flow. As to the quantity aspects, for stocks ranked in the top $30 \%$ of media coverage groups, a one unit change in the previous year's return will bring a 1.1136 unit change in the following year's capital flow, indicating an inflow of capital by investors. Meanwhile, for stocks falling into the bottom $30 \%$ of media coverage groups, a one unit change in the previous year's return will bring a relatively small total effect of 0.0644 units, and this effect is not significant. These results indicate that investors tend to allocate more capital flow in the following year to stocks with high previous year returns. This effect is prominent in the high media coverage portfolios and still holds after controlling for the firm-specific fixed effect caused by firm characteristics such as stock size and book-to-market ratio.

Secondly, as to the quality aspect, under positive media coverage, a one unit increase in the previous year's return can bring a total inflow of 0.5979 units in the following year, after controlling for the firm-specific fixed effect of stock size and book-to-market ratio. This result provides evidence that investors tend to allocate more flow to stocks with high previous year returns, and this effect is remarkable when the media coverage is positive. A reduction in the following year's capital flow is more pronounced in past loser stocks with positive coverage, compared to stocks with similar low return but negative media coverage.

Thirdly, the empirical results of our identification strategy document that the information view doesn't have significant explanatory power, whilst the attention view may shed light on the mechanism of the relationship between media coverage and capital flow.

Overall, this paper has several implications for stock market participants and market efficiency. Contrary to the view that investors use the information contained in media coverage, the results imply that investors' propensity to allocate more capital to high media coverage stocks may be more related to the attention-grabbing function of media coverage. Thus, it may impede the efficiency of the stock market. Also, investors should be more rational when selecting stocks and investigate fundamental operation conditions of the targeted firms instead of following the media, if their time and capacity allows. Nevertheless, firms can benefit from media exposure, especially positive exposure, to attract more investors.

There are some limitations to this study. Though the sample newspapers we select are consistent with internet news content and have an edge in conveying more professional as well as less noisy coverage than their internet counterparts, a more comprehensive sample that includes a variety of mass media, such as newspapers, internet and other public channels, could be adopted to address this issue better. The study may be improved if a detailed time frequency dataset is available. Moreover, this study only used market-based measures of media sentiment for clear analysis; further studies can use both market-based and content-based measures of media sentiment to verify the media sentiment measurement.

\section{Acknowledgement}

The authors thank the editor and anonymous reviewers for valuable comments and suggestions. The authors also acknowledge the support of the National Natural Science Foundation of China (Grant No.71171067 and No.71531013). 


\section{References}

Aman, H. (2011). Firm-specific volatility of stock returns, the credibility of management forecasts, and media coverage: Evidence from Japanese firms. Japan and The World Economy, 23(1), 28-39. doi: 10.1016/j.japwor.2010.06.009.

Bank, M., Larch, M., \& Peter, G. (2011). Google search volume and its influence on liquidity and returns of German stocks. Financial Markets and Portfolio Management, 25, 239-264. doi: 10.1007/s11408-011-0165-y.

Barber, B. M., \& Odean, T. (2008). All that glitters: the effect of attention and news on the buying behavior of individual and institutional investors. The review of financial studies, 21(2), 785-818. doi: 10.1093/rfs/hhm079.

Carretta, A., Farina, V., Martelli, D., Fiordelisi, F., \& Schwizer, P. (2011). The Impact of Corporate Governance Press News on Stock Market Returns. European Financial Management. doi: 10.1111/j.1468-036X.2010.00548.x.

Chan, W. S. (2003). Stock price reaction to news and no-news: drift and reversal after headlines. Journal of Financial Economics, 70(2), 223-260. doi: 10.1016/S0304-405X(03)00146-6.

Chan, Y., Chui, A. C. W., \& Kwok, C. C. Y. (2001). The impact of salient political and economic news on the trading activity. Pacific-basin Finance Journal, 9(3), 195-217. doi: 10.1016/S0927-538X(01)00015-4.

Chen, K., Lu, H., Chen, T., Li, S., Lian, J.,Chen, H. (2011). Giving context to accounting numbers: The role of news coverage. Decision Support Systems, 50(4), 673-679. doi: 10.1016/j.dss.2010.08.025

Cutler, D. M., Poterba, J. M., \& Summers, L. H. (1989). What Moves Stock Prices? Journal of Portfolio Management, 15(3), 4-12. doi: 10.3905/jpm.1989.409212.

Da, Z., Engelberg, J., \& Gao, P. (2011). In Search of Attention. The Journal of Finance, 66(5), 1461-1499. doi: 10.1111/j.1540-6261.2011.01679.x.

Das, S. R., \& Chen. (2007). Yahoo! for Amazon: Sentiment Extraction from Small Talk on the Web. Management Science, 53(9), 1375-1388. doi: 10.1287/mnsc.1070.0704.

Dopuch, N., Holthausen, R. W., \& Leftwich, R. W. (1986). Abnormal stock returns associated with media disclosures of 'subject to'qualified audit opinions. Journal of Accounting and Economics, 8(2), 93-117.

Doran, J. S., Peterson, D. R., \& Price, S. M. (2012). Earnings Conference Call Content and Stock Price: The Case of REITs. Journal of Real Estate Finance and Economics, 41(1), 1-33. doi: 10.1007/s11146-010-9266-z.

Dyck, A., \& Zingales, L. (2003). The media and asset prices: Working Paper, Harvard Business School. (Reprinted.).

Engelberg, J. E., \& Parsons, C. A. (2011). The Causal Impact of Media in Financial Markets. The Journal of Finance, 66(1), 67-97. doi: 10.1111/j.1540-6261.2010.01626.x.

Fang, L. H., Joel, P., \& Lu, Z. (2011). Does Media Coverage of Stocks Affect Mutual Funds'Trading and Performance? Paper presented at the AFA 2011 Denver Meetings Paper.

Fang, L. H., \& Peress, J. (2009). Media Coverage and the Cross-section of Stock Returns. The Journal of Finance, 64(5), 2023-2052. doi: 10.1111/j.1540-6261.2009.01493.x.

Fernandez, B. C., Callen, Y. F., \& Gadea, J. A. L. (2011). Stock Price Reaction to Non-financial News in European Technology Companies. European Accounting Review, 20(1), 81-111. doi: 10.1080/09638180903384650.

Hou, K., Xiong, W., \& Peng, L. (2009). A tale of two anomalies: The implications of investor attention for price and earnings momentum. Available at SSRN 976394.

Kahneman, D. (1973). Attention and effort: Prentice-Hall.

Kerl, A., Schurg, C., \& Andreas Walter. (2014). The impact of Financial Times Deutschland news on stock prices: post-announcement drifts and inattention of investors. Financial Markets and Portfolio Management. Published online

Merton, R. C. (1987). A simple model of capital market equilibrium with incomplete information. The journal of finance, 42(3), 483-510.

Pang, B., Lee, L., \& Vaithyanathan, S. (2002). Thumbs up? Sentiment Classification using Machine Learning Techniques. Computing Research Repository, cs.CL/0205.

Peng, L., \& Xiong, W. (2006). Investor attention, overconfidence and category learning. Journal of Financial Economics, 80(3), 563-602. doi: 10.1016/j.jfineco.2005.05.003.

Pilinkus, D., \& Boguslauskas, V. (2009). The short-run relationship between stock market prices and macroeconomic variables in Lithuania: an application of the impulse response function. Inzinerine Ekonomika-Engineering Economics, 5, 26-33.

Sakalauskas, L., Kalsyte, Z., Vaiciulyte, I., \& Kupciunas, I. (2015). The Relationship between the Transparency in Provision of Financial Data and the Change in Investors' Expectations. Inzinerine Ekonomika-Engineering Economics, 26(1), 33-39.

Solomon, D. H. (2012). Selective publicity and stock prices. The Journal of Finance, 67(2), 599-637. doi: 10.1111/j.1540-6261.2012.01726.x. 
Yang Jiang, Xiangbin Yan. A Firm-Specific Study of the Impact of Media Coverage on Capital Flow

Solomon, D. H., Soltes, E., \& Sosyura, D. (2014). Winners in the spotlight: Media coverage of fund holdings as a driver of flows. Journal of Financial Economics, 112(3), 53.

Stephen, X. H. (2008). The Quantity and Quality of Media Coverage and Its Impact on Stock Price Informativeness and Trading Activity: Evidence from China.

Suleman, M. T. (2012). Stock Market Reaction to Good and Bad Political News. Asian Journal of Finance and Accounting, 4(1), 299-312.

Tetlock, P. C. (2007). Giving Content to Investor Sentiment: The Role of Media in the Stock Market. The Journal of Finance, 62(3), 1139-1168. doi: 10.1111/j.1540-6261.2007.01232.x.

Tetlock, P. C. (2011). All the news that's fit to reprint: do investors react to stale information? The review of financial studies, 24(5), 1481-1512.

Tetlock, P. C., Saar-Tsechansky, M., \& Macskassy, S. (2008). More than Words: Quantifying Language to Measure Firms'Fundamentals. The Journal of Finance, 63(3), 1437-1467. doi: 10.1111/j.1540-6261.2008.01362.x.

Veldkamp, L. L. (2006). Media Frenzies in Markets for Financial Information. American Economic Review, 96(3), 577-601. doi: 10.1257/aer.96.3.577.

Yahui, Z., Difang, W., \& Leiming, F. (2012). An Experimental Study on How Media Reports Affect Investment Behavior Based on Investor Attention. Systems Engineering, 30(10), 19-35.

Zalgiryte, L., Guzavicius, A., \& Tamulis, V. (2014). Stock Market and Economic Growth in the US \& France: Evidence from Stock Market Sector Indices. Inzinerine Ekonomika-Engineering Economics, 25(1), 47-53.

The article has been reviewed.

Received in May 2015; accepted in February, 2016. 